\title{
BMJ Open Which patients receive surgery in for- profit and non-profit hospitals in a universal health system? An explorative register-based study in Norway
}

\author{
Geir Hiller Holom, ${ }^{1,2}$ Nina Alexandersen, ${ }^{1}$ Jeremy D Goldhaber-Fiebert, ${ }^{2}$ \\ Terje P Hagen ${ }^{1}$
}

To cite: Holom GH, Alexandersen N, GoldhaberFiebert JD, et al. Which patients receive surgery in for-profit and non-profit hospitals in a universal health system? An explorative register-based study in Norway. BMJ Open 2018;8:e019780. doi:10.1136/ bmjopen-2017-019780

- Prepublication history and additional material for this paper are available online. To view these files, please visit the journal online (http://dx.doi org/10.1136/bmjopen-2017019780).

Received 24 September 2017 Revised 18 April 2018 Accepted 20 April 2018
Check for updates

${ }^{1}$ Department of Health Economics and Health Management, Institute of Health and Society, University of Oslo, Oslo, Norway

${ }^{2}$ Center for Health Policy and Center for Primary Care and Outcomes Research, Stanford University, Stanford, California, USA

Correspondence to

Dr Geir Hiller Holom; g.h.holom@medisin.uio.no

\section{ABSTRACT}

Objectives To compare the socioeconomic status (SES) and case-mix among day surgical patients treated at private for-profit hospitals (PFPS) and non-profit hospitals (NPS) in Norway, and to explore whether the use of PFPs in a universal health system has compromised the principle of equal access regardless of SES.

Design A retrospective, exploratory study comparing hospital types using the Norwegian Patient Register linked with socioeconomic data from Statistics Norway by using Norwegian citizens' personal identification numbers.

Setting The Norwegian healthcare system.

Population All publicly financed patients in five Norwegian metropolitan areas having day surgery for meniscus (34 100 patients), carpal tunnel syndrome (15 $010)$, benign breast hypertrophy (6297) or hallux valgus (2135) from 2009 to 2014.

Primary outcome measure Having surgery at a PFP or NP.

Results Across four unique procedures, the adjusted odds ratios (aORs) for using PFPs were generally lower for the lowest educational level $(0.77-0.87)$ and the lowest income level (0.68-0.89), though aORs were not always significant. Likewise, comorbidity and previous hospitalisation had lower aORs $(0.62-0.95 ; 0.44-0.97$, respectively) for having surgery at PFPs across procedures, though again aORs were not always significant. No clear patterns emerged with respect to age, gender or higher levels of income and education.

Conclusions The evidence from our study of four procedures suggests that equal access to PFPs compared with NPs for those patients at the lowest education and income levels may be compromised, though further investigations are needed to generalise these findings across more procedures and probe causal mechanisms and appropriate policy remedies. The finding that comorbidity and previous hospitalisation had lower odds of treatment at PFPs indicates that NPs play an essential role for more complex patients, but raises questions about patient preference and cream skimming.

\section{INTRODUCTION}

\section{Background}

The tax-based Norwegian universal health system is built on the principle of equal access
Strengths and limitations of this study

- The study of the free choice of hospital system enables comparisons between private for-profit hospitals (PFP) and non-profit hospitals (NPS) in a universal healthcare system.

- The use of Norwegian citizens' personal identification numbers enables linkage of data from two large and comprehensive nationwide registers allowing the population of publicly financed patients in metropolitan areas to be most accurately represented.

- The explorative focus adds to the limited literature on socioeconomic and case-mix differences between PFPs and NPs in universal health systems, but further research is needed to explain the observed patterns.

to health services regardless of socioeconomic status (SES), ethnicity and geographical residence. ${ }^{i}$ Norway is recognised as an overall top performer among Organisation for Economic Co-operation and Development countries on various health measures and provides a comprehensive coverage of health services for the entire population. ${ }^{1}$ However, substantial challenges related to cost increases and long waiting times for elective surgery prompted Norway's hospital reform and the implementation of a 'free hospital choice system' (FHCS) early in the millennium. ${ }^{2}$ In recent decades, countries with tax-based publicly financed and provided universal healthcare systems have experienced increased attention from private providers. However, limited knowledge exists about the effects of expanding the use of private hospitals in universal health systems. ${ }^{34}$

${ }^{\mathrm{i}}$ The Ministry of Health and Care Services; The Norwegian Patients' Rights Act $§ 1-1$. 
Table 1 Overview of the Norwegian health system

\section{Organisation}

The Norwegian healthcare system is founded on the principles of universal access. The system is mainly financed by taxation and health services are largely provided through public entities.

The system is organised in two administrative layers: the municipalities and the central state. The municipalities (428) are responsible for financing and providing primary care, and the central state (through four RHAs) is responsible for financing and providing specialised health services.

\section{The RHAs own all public hospitals and contracts with PNPs and PFPs. When a PFP wins a contract (usually by competitive tendering), it is included in the Free Hospital Choice System.}

The largest private hospitals are non-profit hospitals with defined catchment areas, mainly funded by the public in a combination of risk-adjusted capitation and activity measured by Diagnosis-Related Groups, similar to public hospitals. The first Norwegian PFP was established in 1985, but had only modest activity until just after the millennium.

\section{Free hospital choice system}

GPs act as gatekeepers responsible for referring patients to specialised health services. Patients having a referral from a GP have the right to freely choose hospitals included in the FHCS, both public and private, owned by or in contract with the RHAs, for the same copay. Maximum total annual copay in 2017 was NOK 2205 ( £200).

GPs are obliged to provide the patient information and recommendations specific to the patient's individual situation. Patients and GPs can access information and guidance about the FHCS (eg, applicable patient rights, hospitals included in the FHCS for specific treatments as well as some waiting time information and quality indicators) by telephone or internet.

The patient has the right to have the referral evaluated by the receiving hospital within ten business days, reduced from 30 days in 2015.

Following the evaluation, the patient is given a time limit for examination and potential treatment. If the time limit is exceeded, the responsible RHA must cover the cost of examination and/or treatment at another hospital domestically or abroad.

FHCS, free hospital choice system; GP, general practitioner; PFP, private for-profit; PNP, private non-profit; RHA, Regional Health Authority.

The Norwegian hospital reform of 2002 formed the basis for outsourcing health services to private for-profit hospitals (PFPs). ${ }^{5}$ The Patients' Rights Act, implemented in 2001, prepared the ground for the implementation of the FHCS. The inclusion of PFPs in the FHCS created a new funding source for PFPs. Inclusion resulted in a substantial increase

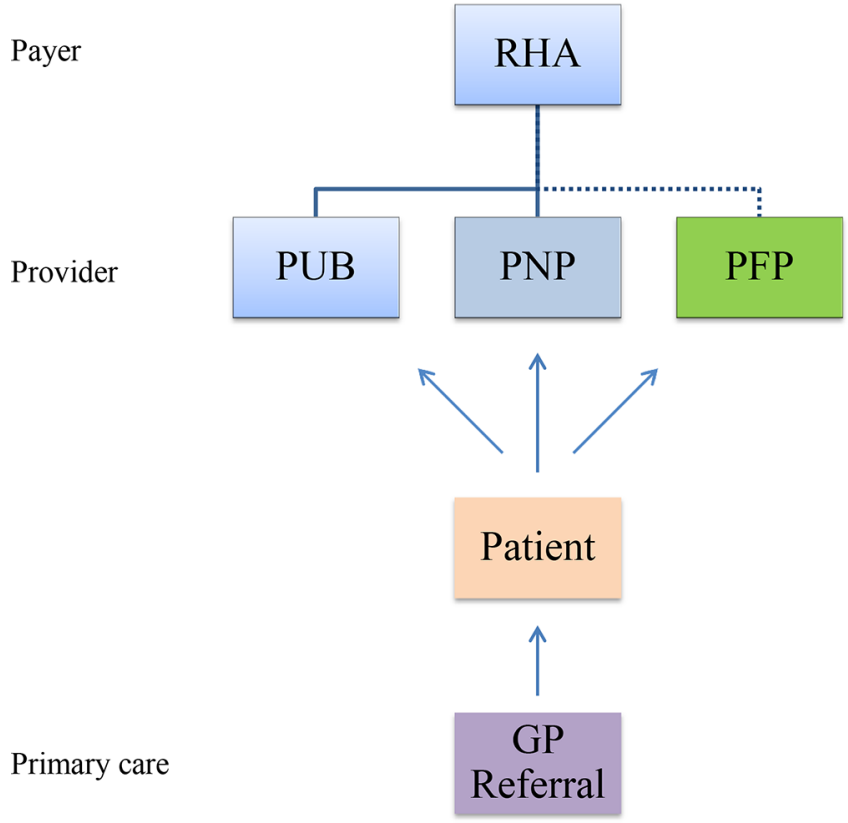

Figure 1 Organisation and the patient choice process. GP, general practitioner; PFP, private for-profit; PNP, private non-profit; PUB, public; RHA, Regional Health Authority. Illustrated by the authors. in the share of total elective day surgeries in Norway performed at PFPs: from $2.2 \%$ in 2001 to $10.4 \%$ in $2014 .{ }^{6}$

In the FHCS, patients with a referral from a general practitioner (GP) for specialised health services have the right to freely choose hospitals, both public and private, owned by or in contract with the Regional Health Authorities (RHAs), for the same copay. ${ }^{5}$ The most salient facts about the Norwegian health system are summarised in table 1.

An overview of the payer-provider relationship and the patient choice process is provided in figure 1. PFPs perform day surgeries at markedly lower prices compared with the national prices used in public hospitals (PUBs). It is believed that these lower prices are, in part, a result of competitive tendering. Potential explanations for the price difference may be: the lack of acute services at PFPs; a less severe patient population; reduced teaching responsibilities, which affects the costs both directly (ie, through lower teaching costs) and indirectly (ie, more experienced surgeons make fewer surgical errors and perform more effective surgery); the ability to streamline production and exploit scaling effects and the ability to hire doctors as independent contractors, reducing downtime and avoiding payroll tax. ${ }^{6}$

Patient waiting time has long been used as an important indicator of access to care. ${ }^{7}$ In general, waiting times decreased in the early years following the hospital reform, ${ }^{\text {ii }}$ but the overall effect of patient choice on waiting times has

\footnotetext{
${ }^{\text {ii }}$ https://www.stortinget.no/nn/Saker-og-publikasjonar/ publikasjonar/Innstillingar/Stortinget/2014-2015/ inns-201415-224/1/\#a1.6.
} 
yet to be demonstrated. ${ }^{8}$ Limited knowledge exists about the effects the increased use of PFPs as a policy option may have on Norway's principle of equal access to health services. However, a report from the Office of the Auditor General of Norway found that $80 \%$ of the patients who chose a PFP faced shorter waiting times compared with the average waiting time for the same procedure at their local hospital. ${ }^{\text {iii }}$

International empirical studies comparing private and public hospitals in universal health systems are relatively limited, differ in their conclusions and are primarily from countries with different healthcare systems than the Nordic system. In Norway, Grotle et al found patients operated on for lumbar discus herniation at private hospitals to be slightly younger and more often male, with a higher level of education and higher likelihood of employment compared with PUBs. However, the indications for surgery appeared similar in both hospital types. ${ }^{9}$ In Denmark, patients having cataract surgery in private versus public hospitals were found to be healthier and younger at the time of their first surgery. ${ }^{10}$ Another Danish study found a significantly higher share of patients aged 35 years and older having arthroscopic meniscal procedures in private compared with public hospitals. ${ }^{11}$ In studies examining private and public hospitals in the comparable English National Health Service, younger patients, a more favourable case-mix (ie, less severe preoperative symptoms and lower levels of comorbidity and American Society of Anesthesiologists classification) and higher SES (ie, more affluent and less likely to come from deprived areas) were generally more common in patients receiving care in PFPs. ${ }^{12-15}$ With regard to different healthcare systems, a recent study in the USA found that PFPs and NPs differ in terms of patient characteristics (including level of education and income) and how care is provided. ${ }^{16}$ Despite certain differences, these prior studies suggest that patients undergoing the same surgical procedures at PFPs and NPs may differ in factors relevant to Norway's principle of equal access regardless of SES.

The aim of the present study was to explore and compare the patient groups who underwent surgical treatments at PFPs with those treated at PNPs and PUBs from 2009 to 2014. We were particularly interested in exploring indications of whether the use of PFPs following the reform-aimed at containing costs and reducing wait times for elective surgery-had compromised the principle of equal access regardless of SES. Due to the many similarities between PNPs and PUBs in terms of organisation, operation (scope of services, departments and teaching responsibilities) and financing scheme, we found it reasonable to analyse these non-profit hospitals

\footnotetext{
iii Riksrevisjonens undersøkelse av ordningen med rett til fritt sykehusvalg, Overlevert Stortinget 20.10.2011.
}

(NPs) together. We analysed where patients received treatment and not whether patients received care overall; hence, efforts to detect explanatory factors for analysed treatment patterns were outside the scope of the exploratory focus of the present study.

We speculated that patients with higher SES may be better at navigating the system and would choose the for-profit alternative when this was viewed as advantageous, for example with regard to shorter wait time. ${ }^{\text {iv }}$ Another potential benefit of using PFPs is that patients are almost always treated by an experienced surgeon. Most Norwegian PFPs exclusively hire fully trained specialists and provide very limited medical training. ${ }^{6}$ We also speculated that, even for the same procedures, PFPs would have a younger, healthier case-mix compared with NPs, due to three main factors: patient preferences, PFP hospitals' contracts and organisation and cream skimming. As none of the Norwegian PFPs have a fully equipped emergency department, they do not contractually treat the most complex patients because the risk of serious complications is considered too high. PFPs may also have a financial incentive to accept younger and less complex patients, since it is generally less expensive to treat less complex patients.

\section{METHODS AND STATISTICS \\ Data sources}

The study cohort was identified through The Norwegian Patient Register (NPR), which contains data on all patients having received treatment at any Norwegian hospital or by a specialist physician. Using Norwegian citizens' mandatory personal identification numbers (PIN), we were able to link individuals to education and income data from Statistics Norway. ${ }^{\mathrm{vi}}$ Information regarding all hospitals announced on the internet as being included in the FHCS was released by the Norwegian Directorate of Health. Strict regulations for handling sensitive data guided our work and each PIN was replaced by a unique, anonymous serial number before research began.

\section{Study population and geographical concentration areas}

We used two criteria to select the study population. First, the procedures had to be included in the FHCS and carried out at both PFPs and NPs between 2009 and 2014. Second, to increase the study's power to detect differences, the procedures had to be performed relatively frequently at both hospitals. Since patients, GPs and surgeons often do not know the exact procedure to be performed at the time of referral and choice of hospital, we selected our patients based on combinations of

\footnotetext{
${ }^{\text {iv }}$ Riksrevisjonens undersøkelse av ordningen med rett til fritt sykehusvalg, Overlevert Stortinget 20.10.2011.

${ }^{\mathrm{v}}$ With their respective RHA.

${ }^{\mathrm{v}}$ Income data was registered from tax returns of all Norwegian residents; The highest level of education achieved by all residents, age 16 and older.
} 

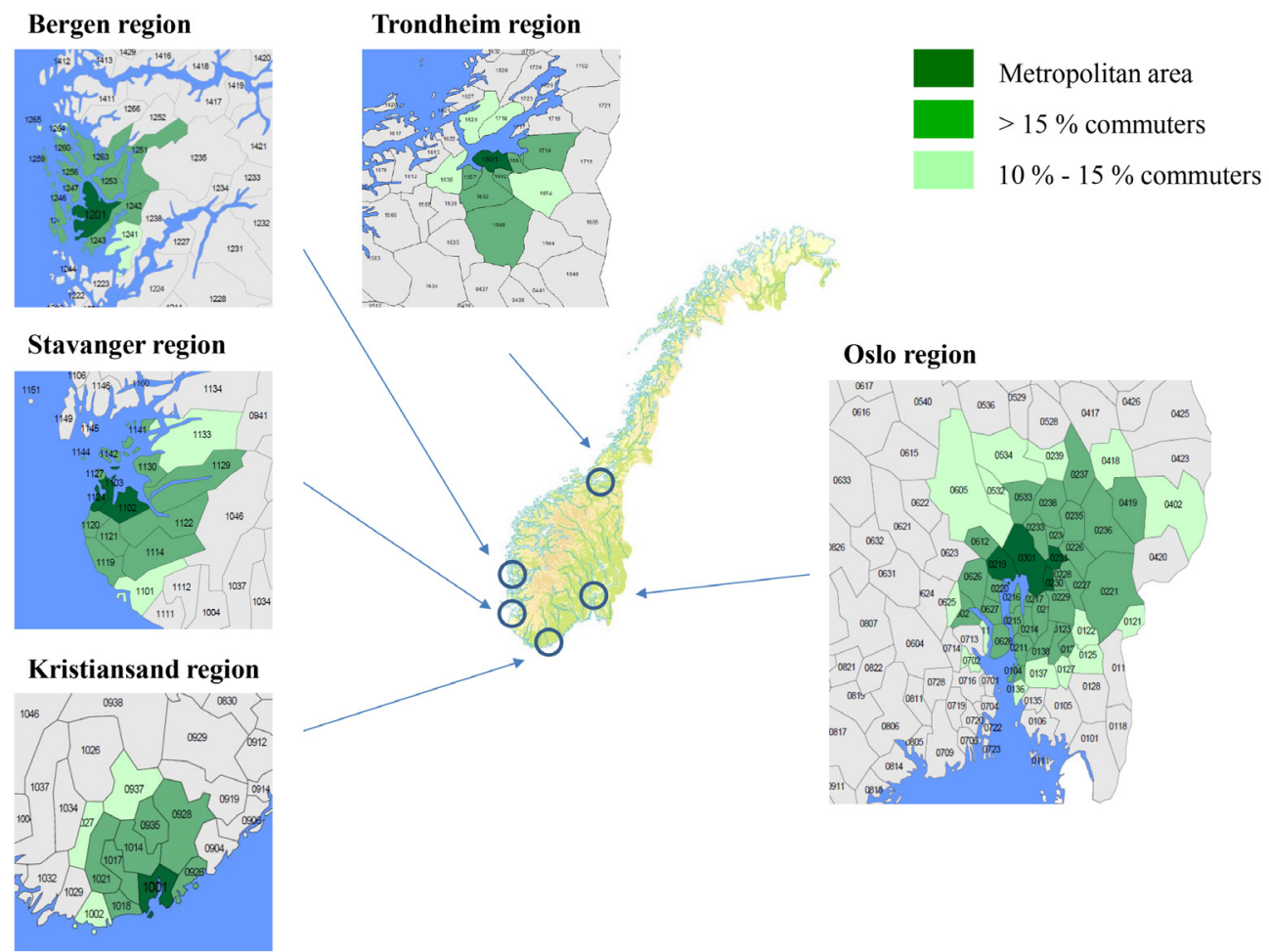

Figure 2 Metropolitan areas. Illustration by Juvkam et $\mathrm{al}^{17}$ : Dark green represents the centre of the metropolitan area; Green represents the areas where more than $15 \%$ of the population regularly commute into the centre area; Light green represents areas where between $10 \%$ and $15 \%$ of the population regularly commute into the centre area.

Diagnosis-Related Group (DRG) and International Statistical Classification of Diseases and Related Health Problems 10th Revision (ICD-10). Based on these criteria, we included all patients with the following DRG and ICD-10 combinations (table 2).

We were interested in comparing publicly financed patients under the FHCS, so patients financed out-ofpocket or by voluntary private health insurance were excluded. Since patients often did not have an option to choose a hospital if the individual set time limit was exceeded and the patients demanded treatment within the time limit, all patients financed under the time limit violation arrangement were also excluded.

We focused on Norway's five metropolitan areas (MAs), where almost all PFPs are located. These regions circle around the cities of Oslo, Trondheim, Bergen, Stavanger and Kristiansand and together host half of Norway's approximately 5.25 million residents. ${ }^{\text {vii }}$ By focusing on MAs, we reduced the bias distance-to-hospital may impose when comparing PFPs and NPs, since distances within these areas are small and comparable between hospitals. The MAs were further divided into subareas using functional boundaries developed by Juvkam et $a l,{ }^{17}$ and we included populations residing in the centre and in areas

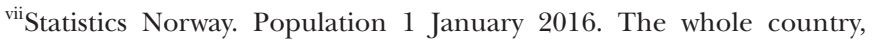
counties and municipalities. https://www.ssb.no/en/befolkning/ statistikker/folkemengde/aar-per-1-januar/2016-02-19? fane=tabell\&sort=nummer\&tabell=256009 (retrieved 20 September 2017).
}

where more than $15 \%$ of residents regularly commute into the centre (figure 2).

\section{Variable definitions}

We treated having surgery at a PFP or NP as our primary outcome measure. Independent variables included income, ${ }^{\text {viii }}$ education, age, gender, comorbidity using the Charlson Comorbidity Index (CCI) and hospitalisation the previous year (HPY) (indicating whether the patient had been hospitalised at any hospital within 365 days

\begin{tabular}{|c|c|c|c|}
\hline \multicolumn{2}{|l|}{ DRG } & \multicolumn{2}{|c|}{ ICD-10 } \\
\hline 2220 & $\begin{array}{l}\text { Day surgery on } \\
\text { humerus, knee, leg/foot }\end{array}$ & M232 & $\begin{array}{l}\text { Derangement of } \\
\text { meniscus due to } \\
\text { old tear or injury }\end{array}$ \\
\hline 60 & $\begin{array}{l}\text { Day surgery for carpal } \\
\text { tunnel syndrome }\end{array}$ & G560 & $\begin{array}{l}\text { Carpal tunnel } \\
\text { syndrome }\end{array}$ \\
\hline 2610 & $\begin{array}{l}\text { Day surgery on benign } \\
\text { mammae (excl. biopsy/ } \\
\text { local excision) }\end{array}$ & N62 & $\begin{array}{l}\text { Hypertrophy of } \\
\text { breast }\end{array}$ \\
\hline 2250 & $\begin{array}{l}\text { Day surgery on ankle } \\
\text { and foot }\end{array}$ & M201 & $\begin{array}{l}\text { Hallux valgus } \\
\text { (acquired) }\end{array}$ \\
\hline
\end{tabular}

ICD-10, International Statistical Classification of Diseases and Related Health Problems 10th Revision.

\footnotetext{
viii Calculated as an arithmetic average of the individual's income in 2000-2008, not adjusted for inflation.
} 
prior to the date of the surgical procedure). The CCI was calculated from main diagnosis or secondary diagnoses ${ }^{18}$ recorded 365 days prior to the date of the procedure and was made binary since the initial analyses revealed a relatively healthy patient group.

\section{Analytical approach and statistical methods}

Mean, SD and frequencies were first used to present an unadjusted description of the patient sample for the four DRG and ICD-10 combinations. We used logistic regression analysis ${ }^{\text {ix }}$ to assess the case-mix as two discrete outcomes-treatment at PFPs versus treatment at NPs-and adjusted for case-mix differences using the described patient-level and socioeconomic covariates. Any missing register data for an individual were handled using the listwise deletion technique. All variables, including the five MAs and year, were treated as fixed effects. The adjusted OR and a 95\% CI were calculated, and we reported per cent concordant (\% C) and Akaike information criterion as goodness-of-fit measures. We performed the analyses using the statistical software SAS V.9.4. ${ }^{\mathrm{x}}$

\section{Patient and public involvement}

The present register-based study was approved by the Norwegian Regional Committees for Medical and Health Research Ethics and the Norwegian Data Protection Authority, who consented to the conduct of the study on behalf of all Norwegian patients.

\section{RESULTS}

\section{Patients and hospital characteristics}

In total, 57542 patients were included. Of these, 24812 patients had surgery at PFPs and 32730 at NPs. Descriptive statistics about the patient sample included in the study are reported in table 3 .

Excepting the benign breast hypertrophy procedure, NPs treated more patients than PFPs did. In unadjusted analyses, PFPs had a lower share of patients with the lowest level of education compared with NPs across procedures. Although patients with upper secondary education were most represented in both PFPs and NPs for two of the procedures, PFPs treated a larger share of patients with an undergraduate level of education than NPs across all procedures. Conversely, except for the carpal tunnel syndrome patient group, PFPs treated a lower share of patients with the highest level of education compared with NPs. PFPs also treated a lower share of patients with income below NOK 200000 compared with NPs, again excepting the carpal tunnel syndrome patient group. Patients with income between NOK 200 and 399999 were represented with a larger share in two procedures at both

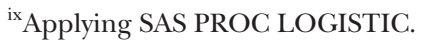

${ }^{\mathrm{x}} \mathrm{SAS}$, Cary, North Carolina, USA.
}

PFPs and NPs, but PFPs treated a larger share of patients with income between NOK 400 and 599999 compared with NPs across all procedures. For patients with income between NOK 600 and 799 999, PFPs and NPs again treated a larger share of patients in two procedures each, while among the highest income group ( $\geq$ NOK 800000 ), PFPs treated a larger share of patients than NPs across procedures, excepting the benign breast hypertrophy patient group.

The share of patients with a CCI score and the share of patients hospitalised the year prior to the procedure were lower at PFPs compared with NPs, across all procedures. Though the share of male patients was lower at PFPs compared with NPs across all procedures, the mean age was highest in two of the procedures at both PFPs and NPs. The descriptive statistics of the five regions are included in the online supplementary tables A1-A4.

\section{Regression analyses}

The odds of having surgery at PFPs were consistently lower across procedures among the lowest educated patients (primary and lower secondary, upper secondary); compared with the reference group (undergraduate), these results were only significant among the primary and lower secondary level patients having meniscus and carpal tunnel surgery and among upper secondary level patients having benign breast hypertrophy surgery. However, the odds of having surgery among patients with the highest level of education (graduate) compared with the reference group had no clear pattern across procedures, but the odds of having surgery at PFPs compared with NPs were significantly lower among the patients with meniscus injury (table 4).

The odds of having surgery at PFPs compared with NPs among patients in the lowest income category $(\leq \mathrm{NOK}$ 199 999) were lower for PFPs compared with NPs across procedures and significantly lower among the patient groups with meniscus and benign breast hypertrophy. When examining the next income level (NOK 200-399 999), we did not find a clear pattern and none of the results were significant. We found neither clear patterns nor significant results among the highest income categories (NOK 600-799 999 and $\geq$ NOK 800000 ). In the second highest income category, the odds were higher for two procedures at both PFPs and NPs, while the odds of having surgery at PFPs compared with NPs for the highest income category were now higher among three of the procedures (excepting patients with carpal tunnel syndrome).

The odds of having surgery at PFPs among patients with a positive CCI score were consistently lower across procedures and significantly lower among the patients with carpal tunnel syndrome and benign breast hypertrophy. The respective odds for previously hospitalised patients were also consistently lower across procedures and significantly lower for all procedures excepting the patients with hallux valgus. 


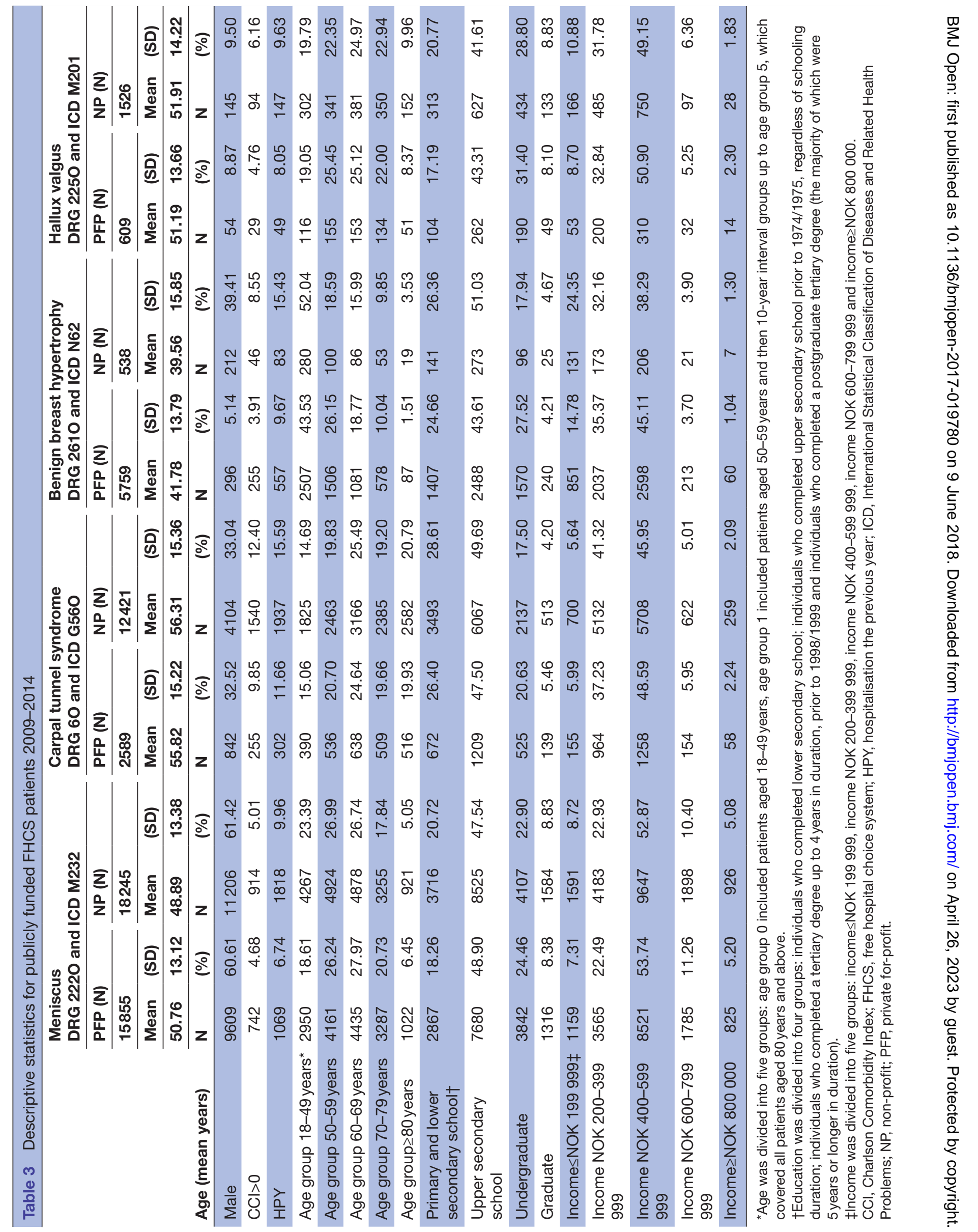


No consistent pattern was found with respect to gender differences. The odds among men were higher for three of the procedures. However, regarding the exceptionpatients with benign breast hypertrophy-men had significantly lower odds of having surgery at PFPs. With respect to age, we had several interesting findings; among the youngest age categories (18-49 and 50-59years), the odds of having surgery at PFPs were higher for three of the procedures compared with the reference group (60-69years). However, the exception-patients with meniscus injury-had significantly lower odds for both age categories. We did not find any consistent patterns among the highest age categories (70-79years and $\geq 80$ years); the odds were higher for two procedures at both PFPs and NPs. We found significantly higher odds among the patients with meniscus injury for both the highest age categories, but significantly lower odds among the patients with benign breast hypertrophy for patients in the highest age category.

\section{DISCUSSION}

\section{Principal findings}

Across four unique procedures, having the lowest level of education (primary and lower secondary; upper secondary school) and being in the lowest income group ( $\leq$ NOK 199 999) were associated with lower odds of using PFPs, though not always significantly. Although the differences could not consistently be distinguished, the evidence from our study suggests that equal access to PFPs compared with NPs for those patients at the lowest income and education levels may be compromised. While we have no reason to believe that these patient groups received no care at all, and as all the other patient groups benefited from the increased capacity PFPs provide (eg, in terms of waiting time), this indicates that Norway's efforts to reduce waiting times and costs may result in difference in access to care. This is especially concerning since low SES patients are in general the most vulnerable patient group and least equipped to navigate in the system. Patients in the lowest income category are below the poverty line defined by the European Union. ${ }^{\mathrm{xi}}$ Some of these patients may not actually be 'low-income' due to family support, assets or other sources of resources, but a national report by Statistics Norway indicates that the majority of individuals below the poverty line in 2014 received social security benefits. ${ }^{19}$ Among the highest educated patients the pattern was unclear, as was the pattern for higher levels of income. However, among patients in the highest income category, the odds of having surgery at PFPs were higher for three of the procedures, but non-significant.

\footnotetext{
${ }^{\mathrm{xi}}$ NOK 207400 in 2014 for a single without children, EU-scale (60 per cent); Statistics Norway. Income and wealth statistics for households, https://www.ssb.no/statistikkbanken/selectvarval/Define. asp? subjectcode $=\&$ ProductId $=\&$ Main Table $=$ LavinntGrenser $\& n-$ $\mathrm{vl}=\&$ PLanguage $=1 \&$ nyTmpVar=true \&CMSSubjectArea=inntekt-og-forbruk\&KortNavnWeb=ifhus $\&$ StatVariant $=\&$ checked $=$ true $\quad($ retrieved 20 September 2017)
}

As expected, patients with a comorbidity included in the CCI and having been hospitalised the year prior to the procedure had consistently lower odds of having surgery at PFPs. While the results were not significant across all procedures, the association indicates that NPs play an essential role for more complex patients. This may be a result of the hospitals and/or the patients themselves efficiently allocating the more complex cases to NPs; however, this raises questions about patient preference and cream skimming and whether these differences are appropriate in terms of both payment levels and achieving the best possible outcomes.

No consistent patterns with respect to age and gender were found across procedures. Although there were significantly lower odds of men having benign breast hypertrophy surgery, indicating less offerings or expertise at PFPs for male patients, the odds among the other procedures were higher, though non-significant. The significant procedure-specific age differences that we found were not consistent in their direction, contradicting findings from previous studies of the Norwegian health system that showed slightly younger patients and patients more likely to be men at private hospitals. ${ }^{90}$ However, these studies were carried out on patients having more complex inpatient surgery, which may explain these age differences.

\section{Strengths and limitations}

The primary strength of our study is our access to the Norwegian Patient Register, which contains information on all patients who have received treatment at all public and private hospitals in Norway. The possibility to link these data to education and income data from Statistics Norway further strengthens our study. These large, unique data sets enable thorough research representing patients residing in MAs within the Norwegian health system. Many other studies on health systems are carried out on a limited group of patients with limited individual data.

While our results regarding hospital type comparisons are valid only for the four procedures analysed and within the specified MAs-thereby not generalisable to all activity in Norway-these procedures are among the most prevalent at both the PFPs and the NPs, making them particularly important to understand in this universal health system. Focusing on MAs also has several advantages: First, most of the PFPs in Norway are located in or close to these MAs; second, half of the Norwegian population resides in one of these regions; third, since distances within these areas are small and comparable between hospitals, this reduces the bias distance-to-hospital may impose when comparing PFPs and NPs. Indeed, Holom and Hagen included all patients in Norway and found significantly fewer patients at private hospitals with increased distance compared with PUBs. ${ }^{20}$ Though Norway is an elongated country and some patients may have considerable distances to the nearest PFP, in the present study, distance's decisiveness should be limited. 


\section{Discussing important differences in the results}

As speculated, three main factors may explain the observed differences: patient preference, PFP hospitals' contracts and organisation and cream skimming.

Patient preference: A patient's choice of healthcare provider is not a straightforward process, but rather a result of the interplay between the patient, the referring GP and provider characteristics. ${ }^{21}$ In a scoping review, Victoor et al found that few patients actively choose their healthcare provider and a substantial fraction consider choice to be unimportant, relying instead on their GP to make the choice. However, more highly educated patients, patients with higher income and younger patients were found to be more active participants in the decision-making process; furthermore, the degree to which patients were capable of processing information rationally was influenced by their ability to obtain, process and understand basic health information and to apply numbers to manage their health. ${ }^{21}$ Patients with higher SES may also put more pressure on their GPs for referrals for specialised services, thus receiving referrals more frequently. ${ }^{22}$

Time spent on waiting lists, staff qualifications and experience $^{21}$ and surgeon reputation ${ }^{23}$ have been found to be important determinants of hospital choice. Additionally, in the Norwegian FHCS, patients with high income and high levels of education are found to be more active in choosing hospitals. ${ }^{\text {xii }}$ Ringard et al found indications that the increased opportunity for hospital choice in the Norwegian FHCS can reduce waiting times and that patients who had neither chosen their hospital personally nor bypassed the local hospital for other reasons had the longest waiting times. From the patient's perspective, when it came to waiting, the least beneficial option was to not choose and consequently end up at the local (NP) hospital. ${ }^{24}$ Most patients are found to face shorter waiting times at PFPs compared with the waiting times they would face for the same procedure at their local (NP) hospital. ${ }^{\text {xii }}$

Ringard et al also found that even if a patient allowed somebody else to decide on his/her behalf-for example, if the referring GP used their knowledge about spare hospital capacity - the waiting time would be reduced if the patient was willing to travel to an alternative hospital. ${ }^{24}$ In the present study, the differences with respect to SES may indicate that information that may have been valuable for helping patients effectively navigate the system were not always effectively attenuated to by GPs. Policies that strengthen patient literacy or train GPs to improve their referral practices may limit these disparities.

The finding that patients who had been hospitalised the year prior to the procedure had lower odds of having surgery at PFPs may also be explained by patients' loyalty to that hospital. Patients may find it more convenient

\footnotetext{
${ }^{x i i}$ Riksrevisjonens undersøkelse av ordningen med rett til fritt sykehusvalg, Overlevert Stortinget 20.10.2011.

xiii Riksrevisjonens undersøkelse av ordningen med rett til fritt sykehusvalg, Overlevert Stortinget 20.10.2011.
}

and comfortable to use a hospital they have already established a relationship with. Victoor et al found that patients tend to rely on previous experiences, with a positive experience positively affecting future choice. ${ }^{21}$ Since NPs provide by far the largest range of treatments in Norway, patients are more likely to have experience with these hospitals. In addition, due to data security, health records in Norway are not shared electronically between hospitals, creating a switching cost both for patients and health providers and providing an incentive for patients to return to hospitals with which they have prior experience.

Private for-profit hospitals' contracts and organisation: Since none of the Norwegian PFPs have a fully equipped emergency department, they do not, by contract, ${ }^{\mathrm{xiv}}$ treat the most complex patients because the risk of serious complications is considered too high. Hospitals must indicate their specific limitations for patient admission in the contracts (ie, comorbidities, ASA classification) and the contracts clearly state that complications and situations requiring more extensive care than PFPs can offer should be referred to an NP. Chard et al discuss that the favourable case-mix among independent sector treatment centres in England (PFPs) is in line with their contracts. ${ }^{13}$ This may explain our finding that CCI and HPY were constantly associated with lower odds of having surgery at PFPs. Furthermore, PFPs in Norway are almost exclusively non-teaching hospitals, ${ }^{6}$ found in the international literature to treat an easier case-mix compared with teaching hospitals. ${ }^{25}$

Cream skimming: The finding that patients who had a positive CCI or had been hospitalised the year prior to the procedure had lower odds of having surgery at PFPs may also be explained by cream skimming. Cream skimming-for example, by excluding complex (unprofitable) patients-has for a long time been discussed as a potential problem with commercialisation of healthcare. ${ }^{26}$ We speculate that PFPs may be unwilling to offer these relatively less complex surgeries to patients with comorbidities that require extra (unprofitable) considerations. On the other side, NPs may be more willing to offer surgery to more complex patients (ie, those requiring extra considerations) if they have prior experience with that patient.

\section{Conclusion and policy implications}

The evidence from our study of FHCS patients having meniscus, carpal tunnel syndrome, benign breast hypertrophy and hallux valgus surgery between 2009 and 2014 in Norway suggests that equal access to PFPs compared with NPs for those patients at the lowest education and income levels may be compromised. Policies that strengthen patient literacy or train GPs to improve their referral practices may help reduce the differences with respect to SES. We did not explicitly test the overall effect of the expansion of PFPs (eg, in terms of shorter waiting

\footnotetext{
${ }^{\mathrm{xiv}}$ With their respective RHA.
} 
times) because we lacked the needed data. However, it is reasonable to expect that such expansion has benefited all patients across the SES spectrum because as more patients are treated in PFPs, one can expect that this would reduce pressure on NPs included in the FHCS and also reduce waiting times for patients. The finding that comorbidity and previous hospitalisation were associated with lower odds of treatment at PFPs indicates that NPs play an essential role for more complex patients. This may be a result of hospitals and/or the patients themselves efficiently allocating the more complex cases to NPs; however, this raises questions about patient preference and cream skimming and whether these differences are appropriate in terms of both payment levels and achieving the best possible outcomes. Further investigations are needed to generalise these findings across more procedures and should go beyond the present explorative scope and include potential explanatory factors (such as waiting time) to explain the observed patterns to further support policy and decision makers in their health management efforts.

Contributors GHH, JDG-F and TPH conceptualised and designed the study. GHH, NA and TPH analysed the data. GHH drafted the manuscript. TPH, JDG-F and NA contributed to the background. All authors reviewed drafts of the article.

Funding The present study was funded by the Research Council of Norway, grant no. 238133.

Competing interests None declared.

Patient consent Not required.

Ethics approval The present study was approved by the Norwegian Regional Committees for Medical and Health Research Ethics and the Norwegian Data Protection Authority.

Provenance and peer review Not commissioned; externally peer reviewed.

Data sharing statement Access to the register data can be sought from the Norwegian Regional Committees for Medical and Health Research Ethics and the Norwegian Data Protection Authority.

Open access This is an Open Access article distributed in accordance with the Creative Commons Attribution Non Commercial (CC BY-NC 4.0) license, which permits others to distribute, remix, adapt, build upon this work non-commercially, and license their derivative works on different terms, provided the original work is properly cited and the use is non-commercial. See: http://creativecommons.org/ licenses/by-nc/4.0/

(c) Article author(s) (or their employer(s) unless otherwise stated in the text of the article) 2018. All rights reserved. No commercial use is permitted unless otherwise expressly granted.

\section{REFERENCES}

1. OECD. Health at a Glance 2015: OECD Indicators: OECD Publishing, 2015.

2. Magnussen J, Vrangbæk K, Saltman R. Nordic Health Care Systems: recent reforms and current policy challenges: McGraw-Hill Education (UK). 2009.
3. Ovretveit J. Nordic privatization and private healthcare. Int J Health Plann Manage 2003;18:233-46.

4. Maarse $H$. The privatization of health care in Europe: an eightcountry analysis. J Health Polit Policy Law 2006;31:981-1014.

5. Hagen TP, Kaarbøe OM. The Norwegian hospital reform of 2002: central government takes over ownership of public hospitals. Health Policy 2006;76:320-33.

6. Hagen TP, Holom GH, Amayu KN. Outsourcing day surgery to private for-profit hospitals: the price effects of competitive tendering. Health Econ Policy Law 2018;13:1-18.

7. Aday LA, Andersen R. A framework for the study of access to medical care. Health Serv Res 1974;9:208.

8. Å R, Sagan A. The 2015 hospital treatment choice reform in Norway: continuity or change? Health policy 2016;120:350-5.

9. Grotle M, Solberg T, Storheim K, et al. Public and private health service in Norway: a comparison of patient characteristics and surgery criteria for patients with nerve root affections due to discus herniation. Eur Spine J 2014;23:1984-91.

10. Solborg Bjerrum S, Mikkelsen KL, la Cour M. Epidemiology of 411 140 cataract operations performed in public hospitals and private hospitals/clinics in Denmark between 2004 and 2012. Acta Ophthalmol 2015;93:16-23.

11. Hare KB, Vinther JH, Lohmander LS, et al. Large regional differences in incidence of arthroscopic meniscal procedures in the public and private sector in Denmark. BMJ Open 2015;5:e006659.

12. Mason A, Street A, Verzulli R. Private sector treatment centres are treating less complex patients than the NHS. J R Soc Med 2010;103:322-31.

13. Chard J, Kuczawski M, Black N, et al. Outcomes of elective surgery undertaken in independent sector treatment centres and NHS providers in England: audit of patient outcomes in surgery. BMJ 2011;343:d6404.

14. Sanjay P, Marioud A, Woodward A. Anaesthetic preference and outcomes for elective inguinal hernia repair: a comparative analysis of public and private hospitals. Hernia 2013;17:745-8.

15. Dawson J, Fitzpatrick R, Gundle R, et al. Provision of primary total hip replacement surgery. Lancet 1999;353:2161.

16. Morris T, McNamara K, Morton $\mathrm{CH}$. Hospital-ownership status and cesareans in the United States: the effect of for-profit hospitals. Birth 2017;44:325-30.

17. Juvkam D, Kann F, Samuelsen R, et al. Storbyregioners funksjonelle grenser: Oslo: Norsk institutt for byog regionforskning, NIBR-rapport. 2011.

18. Quan $\mathrm{H}$, Li B, Couris $\mathrm{CM}$, et al. Updating and validating the Charlson comorbidity index and score for risk adjustment in hospital discharge abstracts using data from 6 countries. Am J Epidemiol 2011;173:676-82.

19. Omholt EL. Økonomi og levekår for ulike lavinntektsgrupper 2016. 2016.

20. Holom GH, Hagen TP. Quality differences between private for-profit, private non-profit and public hospitals in Norway: a retrospective national register-based study of acute readmission rates following total hip and knee arthroplasties. BMJ Open 2017;7:e015771.

21. Victoor A, Delnoij DM, Friele RD, et al. Determinants of patient choice of healthcare providers: a scoping review. BMC Health Serv Res 2012;12:1.

22. Dunlop S, Coyte PC, Mclsaac W. Socio-economic status and the utilisation of physicians' services: results from the Canadian National Population Health Survey. Soc Sci Med 2000;51:123-33.

23. Kandrack R, Mehrotra A, DeVries A, et al. Patient use of cost and quality data when choosing a joint replacement provider in the context of reference pricing. Health Serv Res Manag Epidemiol 2015;2:23.

24. Ringard $\AA$, Hagen TP. Are waiting times for hospital admissions affected by patients' choices and mobility? BMC Health Serv Res 2011;11:170.

25. Zimmerman JE, Shortell SM, Knaus WA, et al. Value and cost of teaching hospitals: a prospective, multicenter, inception cohort study. Crit Care Med 1993;21:1432-42.

26. Relman AS. The new medical-industrial complex. N Engl J Med 1980;303:963-70. 